\title{
A corpus-based deconstructive strategy for critically engaging with arguments
}

\author{
Kieran O'Halloran* \\ Department of Education and Professional Studies, King's College, University of London, \\ Franklin-Wilkins Building, London SE1, UK
}

(Received 2 November 2011; final version received 31 August 2012)

\begin{abstract}
My broad concern is with texts which aim to persuade an audience of a particular point of view on a particular topic - persuasion texts. Political speeches and newspaper editorials are examples of this text type. I put forward a strategy for critically engaging with such texts. Its focus is a persuasion text's cohesion - how it is held together through its vocabulary and grammar. The strategy explores whether or not the cohesion of a persuasion text is unstable, if it deconstructs. Since a persuasion text's credibility is dependent, amongst other things, on effective cohesion, showing where a persuasion text's cohesion deconstructs diminishes its credibility. I call this critical reading strategy Electronic Deconstruction: 'Electronic' reflects the fact that the strategy draws on corpus linguistic method; 'Deconstruction' refers to the deconstructive approach of this strategy. An advantage of Electronic Deconstruction is that it can still facilitate critical engagement with an argument where it is difficult to reconstruct all its premises. This is because its evaluative focus is a persuasion text's cohesive structure rather than its logical structure.

To demonstrate Electronic Deconstruction, the article employs a case-study, a text written in 2008 by the late political journalist, Christopher Hitchens, which justified his continuing support for the 2003 Iraq intervention by US-led coalition forces. After highlighting a number of frustrations in identification of its arguments, and thus for critical assessment of its logical soundness, I show how Electronic Deconstruction as an alternative critical engagement circumvents incomplete reconstruction by doing the following: revealing that the text's cohesive structure is unstable via an electronic deconstructive analysis which draws on a two-billion word corpus, the Oxford English Corpus. The article employs two corpus linguistic software tools: 'Sketchengine' (http://www.sketchengine.co.uk/) and 'WMatrix' (http://ucrel.lancs.ac.uk/wmatrix/).
\end{abstract}

Keywords: cohesion; collocation; corpus linguistic method; electronic deconstruction; obfuscation; rhetorical instability

\section{Introduction}

\subsection{Orientation}

My broad concern is with texts which seek to persuade an audience into a particular point of view on a particular topic, what can be called 'persuasion texts'. Newspaper opinion pieces and political speeches are examples of this text type. I put forward a strategy for critically engaging with persuasion texts, what I refer to as Electronic Deconstruction. Crucially, this strategy draws on corpus linguistic method - the software-based investigation of a collection of electronic texts or 'corpus'. 1

Persuasion texts are a staple of argumentation studies and critical thinking studies. A common procedure in these disciplines is to analyse the logical soundness of arguments in persuasion texts.

*Corresponding author. Email: kieran.o'halloran@kcl.ac.uk 
By 'argument' I mean 'a system of propositions comprising one or more premises advanced by an arguer in support of a conclusion' (Bowell and Kemp 2010, p. 266). Critical assessment of the logical soundness of an argument involves examining whether or not the premises are acceptable and the conclusion drawn from premises is reasonable. In order to do this assessment, an argument's propositions are extracted from persuasion texts. This extraction or identification process is often referred to as the 'reconstruction' of an argument (Bowell and Kemp 2010, pp. 118-168). ${ }^{2}$ After reconstruction, critical assessment of the logical soundness of the argument can proceed.

Electronic Deconstruction takes a different approach to critically engaging with arguments in persuasion texts. Its focus is the cohesion of arguments in persuasion texts - how the arguments are held together through their vocabulary and grammar. For this reason it leaves the language of the persuasion text intact; it does not seek to extract the abstract propositions of the argument(s). Instead, Electronic Deconstruction reveals whether or not a persuasion text's cohesion is unstable, if it deconstructs. It is through comparison of language use in a persuasion text with language use norms in a large corpus that this strategy is able to do this. A persuasion text's credibility is dependent, amongst other things, on the effectiveness of its cohesion. If an electronic deconstructive analysis finds that the cohesive structures of arguments in a persuasion text deconstruct, then the credibility of the text diminishes. ${ }^{3}$ Since this critical reading strategy is deconstructive in focus and draws on corpus linguistic method, I refer to it as 'Electronic Deconstruction'.

\subsection{Circumventing impediments to assessment of logical soundness of arguments}

Sometimes authors make it arduous to reconstruct the argument(s) of a persuasion text. Such difficulties arise for a number of reasons. One, for instance, may be an author's stylistic clumsiness; another might be deliberate obfuscation since the author perceives their argument(s) as weak. The latter might be achieved, for example, through use of vagueness, ambiguity and irrelevance. If an author has inadvertently or deliberately made it arduous for their audience to reconstruct the argument(s) of a persuasion text, assessment of the logical soundness of the argument(s) is hampered since the analyst cannot be sure they have reconstructed all relevant premises. Another standard problem with reconstruction of argument is recovering intended implicit premises ${ }^{4}$; this is especially difficult if the reader cannot easily ascertain the relevance of certain information.

As I have indicated, the evaluative basis of Electronic Deconstruction is the stability of the cohesive structure of a persuasive text rather than the logical soundness of an argument; identifying the cohesive structure of arguments in a persuasion text, as a set of surface features, is often a much more straightforward business than comprehensively capturing the logical structure of argument(s) in a persuasion text. This means that if critical assessment of an argument is hampered by incomplete reconstruction of all premises relevant to a conclusion, Electronic Deconstruction can still potentially facilitate critical engagement with arguments in persuasion texts.

\subsection{Organisation}

I present a case study to demonstrate Electronic Deconstruction.

Section 2 lays out the first part of the strategy of Electronic Deconstruction - the identification of the cohesive structure of arguments in a persuasion text. Since Electronic Deconstruction explores whether there is instability in the cohesive structure of arguments, this first stage is crucial. Section 2 includes the data for the case study, a persuasion text written by the late political journalist, Christopher Hitchens, which in 2008 sought to justify the invasion of Iraq in 2003 by the US-led coalition. Moreover, in Section 2, I employ the corpus linguistic software, WMatrix (http://ucrel.lancs.ac.uk/wmatrix/), not only to help reveal cohesive patterns in a relatively long text, but importantly to reduce selection bias in this procedure. 
In Section 3, I identify Hitchens' arguments in relation to the cohesive structure of the text. I also discuss some problems I encountered in the reconstruction of his arguments.

Section 4 outlines the theory and method of Electronic Deconstruction - the use of a large corpus to illuminate where a persuasion text's cohesion is unstable.

Section 5 demonstrates an electronic deconstructive analysis, revealing instability in the cohesive structure of Hitchens' text and how this diminishes its credibility. Electronic deconstructive analysis in Section 5 draws on a two-billion word corpus, the Oxford English Corpus, and employs the corpus linguistic software 'Sketchengine' (http://www.sketchengine.co.uk/) to search through this corpus. Despite some problems experienced in reconstruction of the arguments, I show how an electronic deconstructive analysis is still able to facilitate critical engagement with Hitchens' text.

\section{Electronic deconstruction I: identifying the cohesive structure of a persuasion text}

\subsection{Orientation}

Hitchens' text is titled 'How did I get Iraq wrong? I didn't'. It appeared in Slate.com, an Englishlanguage online current affairs and culture magazine, on $17^{\text {th }}$ March 2008. ${ }^{5}$ Here is the editor's note which appeared above Hitchens' piece:

To mark the fifth anniversary of the invasion of Iraq, Slate has asked a number of writers who originally supported the war to answer the question, 'Why did we get it wrong?' We have invited contributions from the best-known 'liberal hawks',...

Slate.com is affiliated to The New York Times; Christopher Hitchens, though born in the UK, also held American citizenship (which explains his use of the inclusive 'we' in the text). The text is 1171 words in length including the title. There are seven paragraphs in total, which I have labelled A-G. There are 35 sentences; numbers in square brackets below and in the rest of the article refer to sentence numbers in Hitchens' text. Underlined text in Hitchens' article indicates a hyperlink to a website.

Title: 'How did I get Iraq wrong? I didn't'.

Paragraph A

[1] An 'anniversary' of a 'war' is in many ways the least useful occasion on which to take stock of something like the Anglo-American intervention in Iraq, if only because any such formal observance involves the assumption that a) this is, in fact, a war and b) it is by that definition an exception from the rest of our engagement with that country and that region.

[2] I am one of those who, for example, believes that the global conflict that began in August 1914 did not conclusively end, despite a series of 'fragile truces', until the fall of the Berlin Wall and the collapse of the Soviet Union.

[3] This is not at all to redefine warfare and still less to contextualize it out of existence.

[4] But when I wrote the essays that go to make up A Long Short War: The Postponed Liberation of Iraq, I was expressing an impatience with those who thought that hostilities had not really 'begun' until George W. Bush gave a certain order in the spring of 2003.

\section{Paragraph B}

[5] Anyone with even a glancing acquaintance with Iraq would have to know that a heavy U.S. involvement in the affairs of that country began no later than 1968, with the role played by the CIA in the coup that ultimately brought Saddam Hussein's wing of the Baath Party to power.

[6] Not much more than a decade later, we come across persuasive evidence that the United States at the very least acquiesced in the Iraqi invasion of Iran, a decision that helped inflict moral and material damage of an order to dwarf anything that has occurred in either country recently.

[7] In between, we might note minor episodes such as Henry Kissinger's faux support to Kurdish revolutionaries, encouraging them to believe in American support and then abandoning and betraying them in the most brutal and cynical fashion. 


\section{Paragraph $C$}

[8] If you can bear to keep watching this flickering newsreel, it will take you all the way up to the moment when Saddam Hussein, too, switches sides and courts Washington, being most in favor in our nation's capital at the precise moment when he is engaged in a campaign of extermination in the northern provinces and retaining this same favor until the very moment when he decides to 'engulf' his small Kuwaiti neighbor.

[9] In every decision taken subsequent to that, from the decision to recover Kuwait and the decision to leave Saddam in power to the decisions to impose international sanctions on Iraq and the decision to pass the Iraq Liberation Act of 1998, stating that long-term coexistence with Saddam's regime was neither possible nor desirable, there was a really quite high level of public participation in our foreign policy.

[10] We were never, if we are honest with ourselves, 'lied into war'.

[11] We became steadily more aware that the option was continued collusion with Saddam Hussein or a decision to have done with him.

[12] The president's speech to the United Nations on Sept. 12, 2002, laying out the considered case that it was time to face the Iraqi tyrant, too, with this choice, was easily the best speech of his two-term tenure and by far the most misunderstood.

\section{Paragraph $D$}

[13] That speech is widely and wrongly believed to have focused on only two aspects of the problem, namely, the refusal of Saddam's regime to come into compliance on the resolutions concerning weapons of mass destruction and the involvement of the Baathists with a whole nexus of nihilist and Islamist terror groups.

[14] Baghdad's outrageous flouting of the resolutions on compliance (if not necessarily the maintenance of blatant, as opposed to latent, WMD capacity) remains a huge and easily demonstrable breach of international law.

[15] The role of Baathist Iraq in forwarding and aiding the merchants of suicide terror actually proves to be deeper and worse, on the latest professional estimate, than most people had ever believed or than the Bush administration had ever suggested.

\section{Paragraph E}

[16] This is all overshadowed by the unarguable hash that was made of the intervention itself.

[17] But I would nonetheless maintain that this incompetence doesn't condemn the enterprise wholesale.

[18] A much-wanted war criminal was put on public trial.

[19] The Kurdish and Shiite majority was rescued from the ever-present threat of a renewed genocide.

[20] A huge, hideous military and party apparatus, directed at internal repression and external aggression, was (perhaps overhastily) dismantled.

[21] The largest wetlands in the region, habitat of the historic Marsh Arabs, have been largely recuperated.

[22] Huge fresh oilfields have been found, including in formerly oil-free Sunni provinces, and some important initial investment in them made.

[23] Elections have been held, and the outline of a federal system has been proposed as the only alternative to a) a sectarian despotism and b) a sectarian partition and fragmentation.

[24] Not unimportantly, a battlefield defeat has been inflicted on al-Qaida and its surrogates, who (not without some Baathist collaboration) had hoped to constitute the successor regime in a failed state and an imploded society.

[25] Further afield, a perfectly defensible case can be made that the Syrian Baathists would not have evacuated Lebanon, nor would the Qaddafi gang have turned over Libya's (much higher than anticipated) stock of WMD if not for the ripple effect of the removal of the region's keystone dictatorship.

\section{Paragraph $F$}

[26] None of these positive developments took place without a good deal of bungling and cruelty and unintended consequences of their own. 
[27] I don't know of a satisfactory way of evaluating one against the other any more than I quite know how to balance the disgrace of Abu Ghraib, say, against the digging up of Saddam's immense network of mass graves.

[28] There is, however, one position that nobody can honestly hold but that many people try their best to hold.

[29] And that is what I call the Bishop Berkeley theory of Iraq, whereby if a country collapses and succumbs to trauma, and it's not our immediate fault or direct responsibility, then it doesn't count, and we are not involved.

[30] Nonetheless, the very thing that most repels people when they contemplate Iraq, which is the chaos and misery and fragmentation (and the deliberate intensification and augmentation of all this by the jihadists), invites the inescapable question: What would post-Saddam Iraq have looked like without a coalition presence?

\section{Paragraph $G$}

[31] The past years have seen us both shamed and threatened by the implications of the Berkeleyan attitude, from Burma to Rwanda to Darfur.

[32] Had we decided to attempt the right thing in those cases (you will notice that I say 'attempt' rather than 'do', which cannot be known in advance), we could as glibly have been accused of embarking on 'a war of choice'.

[33] But the thing to remember about Iraq is that all or most choice had already been forfeited.

[34] We were already deeply involved in the life-and-death struggle of that country, and March

2003 happens to mark the only time that we ever decided to intervene, after a protracted and open public debate, on the right side and for the right reasons.

[35] This must, and still does, count for something. [@The New York Times 2008]

\subsection{Using WMatrix software to help identify cohesive patterns in Hitchens' text as a precursor to electronic deconstructive analysis}

\subsubsection{Cohesion and semantic domains}

As I indicated in the introduction, cohesive structure is a key focus for electronic deconstructive analysis of a persuasion text, so I shall need to establish this for Hitchens' text.

'Cohesion' is a linguistic term used to refer to how a text holds together semantically through lexical features as well as through grammatical features (Halliday and Hasan 1976). ${ }^{6}$ For example, in the following short text, each sentence is linked by the lexical words 'decided' and 'decision' as well as by the grammatical words 'him' and 'he' (referring back to 'Jack') and 'she' (referring back to 'Jill'):

Jack decided finally to ask Jill to marry him. Naturally, he was pleased with this decision as she said 'yes'.

It is usually easy to spot cohesion in a short text such as in the example above. However, with a much longer text, it can be quite laborious to identify far-reaching patterns of cohesion. Moreover, human fallibility means we may miss aspects of a global cohesive pattern. In other words, what we identify as a cohesive pattern in a relatively long text may well involve selection bias.

While identifying cohesive patterns across a text is, ultimately, a qualitative procedure, I will show how quantitative data about the text can significantly reduce selection bias in this identification. In relation to Hitchens' text, my qualitative identification of global cohesive patterns will be assisted with quantitative data generated using the corpus linguistic software, WMatrix (Rayson 2009). There are a number of different forms of corpus linguistic software. What makes WMatrix different from other corpus linguistic software tools is that it can analyse a text's 'semantic domains' - sets of different words of related meaning. WMatrix does this by grouping semantically similar words together using 'a semantic tagger'. ${ }^{7}$ This is a software program which brackets words into general semantic domains on the basis of a pre-configured lexicon. So, for example, 
with the semantic tagger that WMatrix uses, the words, 'war', 'weapons', 'military' are tagged with the general semantic domain 'WARFARE, DEFENCE AND THE ARMY'. Semantically similar words provide cohesion across a text. That WMatrix groups semantically similar words in this way can significantly reduce labour and selection bias in identifying cohesive patterns across a text.

\subsubsection{Semantic domains and statistical significance}

WMatrix also has access to what is known as reference corpora. ${ }^{8}$ A reference corpus is a large electronic collection of texts from the same language which has been sampled across a variety of genres. Because of this, a reference corpus is seen as a representative snapshot of a language, a norm of language use. A reference corpus, just like a single text, can be tagged for its semantic domains. Using WMatrix to compare semantic domains in a text with the semantic domains of a reference corpus illuminates the statistical significance of the former. If a semantic domain in a persuasion text is statistically significant, this can help the analyst see the furthest reaching cohesive patterns in a relatively long text. This is useful since it is the software which is doing a good deal of the work here, not the fallible and subjective human being.

The largest written reference corpus in WMatrix has one million words. ${ }^{9}$ It has been tagged for semantic information. The statistical metric used in WMatrix is log likelihood (see Dunning 1993). In WMatrix, a log likelihood value of $\geq 7$ is statistically significant $(p<0.01)^{10}$; so if a semantic domain in a text is found to have a log likelihood value of $\geq 7$, then this semantic domain is statistically significant. Lastly, the size of the log likelihood value $\geq 7$ is proportional to the statistical significance of the linguistic item.

For the purposes of trying to identify cohesive patterns in a relatively long text, not all statistically significant semantic domains which WMatrix generates are worth examining. This is because the number of words subsumed under even a statistically significant semantic domain may be only 1 and so this word is unlikely to be contributing significantly to global cohesive structure. Conversely, where log likelihood is both in excess of 7 and word frequency is more than 1, then this could be worth exploring and especially so if word frequency is far in excess of 1 .

Table 1 contains all the semantic domains in Hitchens' text which have statistical significance, i.e. over a $\log$ likelihood value of 7 , and where the frequency for words subsumed under the semantic domains is greater than 1. Clearly, words subsumed, for example, under the semantic domain DECIDED (log likelihood, 36.5; frequency 12) will be worth investigating for their contribution to the cohesion of Hitchens' text.

\subsubsection{Care in use of quantitative data}

Care needs to be exercised in basing judgements of cohesion on the basis of tagged data. First, the tagger that WMatrix uses has an accuracy of $92 \%$. Second, being a software programme with a pre-configured lexicon, the semantic tagger has little scope for the kind of discerning semantic judgements that a human mind can make. Human judgements of cohesive patterning may be based on contextual information, something which a tagger is limited in replicating. For example, in the PARTICIPATING semantic domain (see Table 1), the words 'intervention' [1], 'participation' [9], 'intervention' [16] and 'intervene' [34] are part of a cohesive chain in Hitchens' text which relates to US ('our') involvement in Iraq, while 'collaboration' [24] is not. Conversely, because a semantic tagger cannot judge meanings in a text contextually, it may choose a semantic domain for a word in a text which a human would not - and vice versa.

In a nutshell, the tagging facility of WMatrix is very useful because it helps the analyst comprehensively to track cohesive patterns across relatively large texts and in so doing significantly 
Table 1. Statistically significant semantic domains in Hitchens' text where the total of words subsumed under the semantic domains is greater than 1 .

\begin{tabular}{|c|c|c|c|}
\hline Semantic domain & Log likelihood & Frequency & $\begin{array}{l}\text { Words in semantic domain potentially feeding into } \\
\text { a cohesive pattern (numbers in curved brackets indicate } \\
\text { individual word frequency) }\end{array}$ \\
\hline DECIDED & 36.5 & 12 & $\begin{array}{l}\text { decision (5), resolutions (2), decided (2), decides (1), } \\
\text { decision_taken (1), decisions (1). }\end{array}$ \\
\hline TIME: GENERAL & 18.0 & 3 & ever (3). \\
\hline SIZE: BIG & 13.7 & 4 & huge (3), largest (1). \\
\hline $\begin{array}{l}\text { GEOGRAPHICAL } \\
\text { NAMES }\end{array}$ & 9.8 & 31 & $\begin{array}{l}\text { Iraq (10), Kurdish (2), Iraqi (2), Washington (1), } \\
\text { Northern_provinces (1), Kuwaiti (1), Kuwait (1), } \\
\text { nation (1), Baghdad (1), marsh (1), Arabs (1), Syrian } \\
\text { (1), Lebanon (1), Libya (1), Burma (1), Rwanda (1), } \\
\text { Berlin (1), Soviet (1), Iran (1), American (1). }\end{array}$ \\
\hline $\begin{array}{l}\text { WARFARE, DEFENCE } \\
\text { AND THE ARMY }\end{array}$ & 9.6 & 11 & $\begin{array}{l}\text { war (5), war_criminal (1), military (1), weapons (1), } \\
\text { battlefield (1), warfare (1), invasion (1). }\end{array}$ \\
\hline NEGATIVE & 9.3 & 20 & $\begin{array}{l}\text { not (11), n't (3), nor (2), neither (1), none (1), not_really } \\
\quad(1) \text {, no (1). }\end{array}$ \\
\hline TIME: NEW and YOUNG & 8.3 & 3 & latest (1), recently (1), revolutionaries (1). \\
\hline PARTICIPATING & 7.6 & 5 & $\begin{array}{l}\text { intervention (2), participation (1), collaboration (1), } \\
\text { intervene (1). }\end{array}$ \\
\hline $\begin{array}{l}\text { QUANTITIES: } \\
\text { MANY/MUCH }\end{array}$ & 7.1 & 4 & most (6), majority (1). \\
\hline
\end{tabular}

reduce labour and selection bias. But, it is important to make sure that the software analysis of semantic meaning is corroborated by human judgements of semantic meaning. In Section 3, I bear all this in mind when I identify arguments in Hitchens' text in relation to their cohesive structure.

\section{Electronic deconstruction II: identifying arguments in relation to cohesive structure}

\subsection{Reconstructing Hitchens' arguments via their cohesive structures}

\subsubsection{Not 'extracting' propositions, but leaving cohesion intact}

I identify Hitchens' persuasion text as consisting of three sub-arguments, two of which (and possibly all three) are related via a Supra-argument; I order my identification of these arguments as they appear in Hitchens' text.

In my reconstruction, I do not 'extract' premises from the sentences as is often the case in argumentation studies and critical thinking studies (e.g. Walton 2006; Bowell and Kemp 2010). This is because my focus, in Section 5, will be on exploring whether or not the cohesive structure of arguments in Hitchens' text is unstable. For this reason, in my identification, I keep the language of the text and thus its cohesive devices almost completely intact, relating it to words from the semantic domains in Table 1 as appropriate. (Where I make alterations to Hitchens' text in premise identification is, largely, in transforming a clause into subject-predicate form.) In taking account of the language of the text in my reconstruction of the argument, I accord with Scott Jacobs' normative pragmatics (e.g. Jacobs 2000, 2009).

\subsubsection{Sub-argument 1: the 2003 Anglo-American intervention in Iraq was not an exception from US involvement in Iraq and so not a discrete war}

Premise: A war between two countries is by definition an exception in how those two countries engage with one another. [1] 
Premise: Hostilities did not begin in 2003 (though it is unclear in Hitchens' text when they did begin). [4]

Premise: Heavy US involvement in the affairs of Iraq began no later than 1968. [5]

Premise: [There was] a decision by the US to acquiesce in the Iraqi invasion of Iran. [6]

Premise: Kissinger [gives] faux support for Kurdish revolutionaries. [7]

Premise: Saddam Hussein courts Washington. [8]

Premise: Saddam Hussein decides to 'engulf' Kuwait. [8]

Premise: There was a really quite high level of public participation in US foreign policy in decisions taken to recover Kuwait, the decision to leave Saddam in power; the decision to impose international sanctions on Iraq; the decision to pass the 1998 Iraq Liberation Act. [9]

Premise: Baghdad outrageous[ly] flouted the resolutions on WMD compliance. [13,14]

Premise: 'We became steadily more aware that the option was continued collusion with Saddam or a decision to have done with him'. [11]

Conclusion: We were never... 'lied into war' [10], i.e., the 'Anglo-American intervention in Iraq' [1] was not a discrete war but a continuation of US involvement in Iraq since (no later than) 1968. [my bold]

The repetition of words subsumed under the statistically significant semantic domain DECIDED is a crucial part of the cohesion of Sub-argument 1 (see Table 1 and bold above). In other words, US involvement in Iraq since 1968 is constructed as a series of decisions. There are also terms from the statistically significant semantic domain WARFARE, DEFENCE AND THE ARMY (see Table 1 and underlining above) such as in "never..."lied into war" [10]) which, not surprisingly, are in cohesion with one another given that Hitchens' argument involves negating that the US-led coalition intervention of Iraq was a discrete war. (Moreover, there are terms in Sub-argument 1 from the statistically significant semantic domain NEGATIVE (see Table 1 and italics above) though these do not provide textual cohesion).

\subsubsection{Sub-argument 2: although incompetent, the Iraq intervention has positives}

Premise: A much-wanted war criminal was put on public trial. [18]

Premise: The Kurdish and Shiite majority was rescued from the ever-present threat of a renewed genocide. [19]

Premise: A huge, hideous military and party apparatus, directed at internal repression and external aggression was (perhaps overhastily) dismantled. [20]

Premise: The largest wetlands in the region, habitat of the historic Marsh Arabs, have been largely recuperated. [21]

Premise: Huge fresh oilfields have been found, including in formerly oil-free Sunni provinces, and some important initial investment in them made. [22]

Premise: Elections have been held, and the outline of a federal system has been proposed as the only alternative to a) a sectarian despotism and b) a sectarian partition and fragmentation. [23]

Premise: Not unimportantly, a battlefield defeat has been inflicted on al-Qaida and its surrogates, who (not without some Baathist collaboration) had hoped to constitute the successor regime in a failed state and an imploded society. [24]

Premise: Further afield, a perfectly defensible case can be made that the Syrian Baathists would not have evacuated Lebanon, nor would the Qaddafi gang have turned over Libya's (much higher than anticipated) stock of WMD if not for the ripple effect of the removal of the region's keystone dictatorship. [25]

Conclusion: Although the prosecution of the intervention 'was a hash', the whole enterprise should not be condemned. [16,17]

This argument is directly relevant to the title of Hitchens' argument: 'How did I get Iraq wrong? I didn't'. That is, in Sub-argument 2, Hitchens provides a series of reasons why, in his opinion, 
positives flowed from the intervention. Despite the absence of a conclusion marker, the conclusion is easy to identify and Hitchens' post hoc reasons for the validity of the Iraq invasion are laid out neatly in sequence in paragraph E [18-25]. Three terms from the statistically significant semantic domain, WARFARE, DEFENCE AND THE ARMY, are used (bolded above). The first two - 'war criminal' and 'military (apparatus)' - link Saddam Hussein in war/military terms. Three of the four terms from the semantic domain, SIZE: BIG, feature in Sub-argument 2 (italicised above). These provide cohesion across Sub-argument 2, perhaps rhetorically, to the extent that the positives of the intervention were sizeably significant.

\subsubsection{Sub-argument 3: implication of moral superiority of Iraq intervention}

Premise: If a country collapses and succumbs to trauma and it's not our direct responsibility then we are not involved (Bishop Berkeley theory of Iraq). [29]

Premise: Saddam Hussein was a genocidist. [8, 19, 27]

Premise: We have been shamed by the implications of the Berkeleyan attitude from Burma to Rwanda to Darfur. [31]

Implicit premise?: Potential interventions into Burma, Rwanda or Darfur would be humanitarian.

Premise: Had we decided to attempt the right thing in Burma, Rwanda, Darfur, we could as glibly have been accused of embarking on a 'war of choice'. [32]

Implicit premise?: Potential (humanitarian) interventions into Burma, Rwanda or Darfur would have a moral basis.

Premise: All choice had been forfeited re Iraq. [33]

Premise: We were already deeply involved in the life-and-death struggle of that country, and March 2003 happens to mark the only time the US ever decided to intervene, after a protracted and open public debate, on the right side and for the right reasons. [34]

Implied conclusions: ? The intervention into Iraq was morally superior to the absence of humanitarian interventions into Burma, Rwanda and Darfur;

? The intervention into Iraq was humanitarian.

There are two instances of words from the semantic domain DECIDED (bolded above) which facilitate cohesion in Sub-argument 3. There is one instance of a term from WARFARE, DEFENCE AND THE ARMY (italicised above). This instance - 'war' - is in the expression 'war of choice', which Hitchens places in inverted commas. Hitchens' qualification of 'war' here links back to the qualified use of 'war' in Sub-argument 1. (In Section 3.1.5, I discuss use of 'intervene' - see last premise above - a word from the PARTICIPATING semantic domain.)

I found Sub-argument 3 harder to reconstruct than the previous two sub-arguments, hence why I use question marks around the conclusion and my recovery of implicit premises. I shall discuss my reconstruction frustrations in Section 3.2.

\subsubsection{Supra-argument: links to the sub-arguments}

The last substantive sentence in the argument is [34]:11

[34] We were already deeply involved [cohesive link to Sub-argument 1 and 3] in the life-anddeath struggle [cohesive link to Sub-argument 3] of that country, and March 2003 happens to mark the only time that we ever decided [cohesive link to Sub-argument 1] to intervene [cohesive link to Sub-argument 1], after a protracted and open public debate, on the right side and for the right reasons [cohesive link to Sub-argument 2?]. [my bold]

I would argue that [34] is not only a key sentence in Sub-argument 3, but is also a significant sentence for the entire persuasion text; it has an important function in finalising the stitching of 
Sub-arguments 1 and 3 together. A quantitative reason for this judgement is that [34] links back to terms from the statistically significant semantic domains DECIDED and PARTICIPATING in Sub-argument 1. In [34], there are the following cohesive links with Sub-argument 1:

(1) 'decided' with words subsumed under DECIDED [6,9,11,13,14] - see Table 1;

(2) 'intervene' with 'Anglo-American intervention in Iraq' [1], i.e. linkage with a word subsumed under PARTICIPATING - see Table 1) ('Intervene' in [34] also links with 'intervention' [16]).

(3) 'protracted and open public debate' with 'really quite high level of public participation in our foreign policy' [9], i.e. with a word subsumed under PARTICIPATING.

(4) 'involved' with 'US involvement in the affairs of [Iraq]' [5].

In the Supra-argument, Hitchens constructs the 2003 'decision to intervene' [34] as another decision in a series of them taking place in US involvement in Iraq since (no later than) 1968. In Section 3.2, I discuss some difficulties I experienced in identifying the Supra-argument - flagged by the use of '?' above and below.

I attempt an interpretation of the Supra-argument as follows: on my account, it consists of two conclusions - major and minor. Here is my reconstruction of its structure:

a)

Sub-argument 1

$+$

Sub-argument 3

Major Conclusion: The 2003 'Anglo-American intervention in Iraq' [1] is not 'an exception from the rest of our [US] engagement with that country and that region' [1] but one of a number of 'death struggles' [34] that the US has been involved in with that country since (no later than) 1968 [5] e.g., when it was in conflict with Iraq - although the US was involved in the 'life struggles' [34] of Iraq too - e.g., when it acquiesced in the Iraqi invasion of Iran [6].

b)

Premises: 'Saddam's regime refused to come into compliance on the resolutions concerning weapons of mass destruction' [13];

'[There was] involvement of the Baathists with a whole nexus of nihilist and Islamist terror groups'. [13]

$+$

? Other reasons from Bush's speech to the UN which Hitchens does not mention.

$+$

? Sub-argument 2.

$+$

Sub-argument 3.

Minor conclusion: 'The 2003 'Anglo-American intervention in Iraq' [1] took place 'on the [morally] right side and for the [morally] right reasons' [34].

Having identified the arguments in relation to their cohesive structure, I could just jump to Sections 4 and 5 and explore whether or not there is instability in the cohesive structure of these arguments; if the cohesive structure deconstructs, the arguments in the persuasion text thus reduce in credibility. In Section 3.2, however, I discuss some problems I experienced with my identification of the logical structure of Hitchens' arguments which, in turn, would hinder critical assessment of their logical soundness. The reason for this discussion is so the reader will appreciate how, in Section 5, electronic deconstructive analysis of the text circumvents such problems by still potentially facilitating a form of critical engagement with a persuasion text. 


\subsection{Problems in identifying Hitchens' arguments}

\subsubsection{Sub-argument 3 and implication of moral superiority of Iraq intervention}

3.2.1.1 Relevance of the references to Burma, Darfur, Rwanda. Interventions in Burma, Darfur (a region of Sudan) and Rwanda - if they had occurred - would have been humanitarian ones for the purposes of preventing (worsening) genocide. ${ }^{12}$ By not modifying 'intervene' [34], 'involved' [29] etc and, at the same time, making analogy with Burma, Darfur and Rwanda, Hitchens seems to be implying that the Iraq intervention was superior to the absence of humanitarian interventions in those countries and perhaps also that the Iraq intervention was a kind of humanitarian intervention. ${ }^{13}$ This is maybe why Hitchens includes references to Saddam Hussein as a genocidist $[8,19,27]$ ? It is difficult to know for sure. Moreover, Hitchens appears to be suggesting through 'shamed' [31] and 'on the right side and for the right reasons' [34] that the Iraq intervention was a more moral moment than the absence of interventions in Burma, Darfur and Rwanda. Again, I cannot be completely sure of this. Because of the allusiveness of Sub-argument 3, this is why I put question marks around my identification of implicit premises and conclusions (see Section 3.1.4).

3.2.1.2 Doctor (US) and patient (Iraq) metaphor and vagueness. In Sub-argument 3, Hitchens uses an extended medical metaphor where the US is a quasi-doctor who 'intervenes' [34] in the 'traumatised' [29] Iraq, the US having had 'responsibility' [29] and 'involvement' [29,34] for this quasi-patient's 'life and death struggle' [34]. Note, though, the vagueness of the medical metaphor in [29]. What exactly does Hitchens intend the reader to understand by 'if a country... succumbs to trauma'? This vagueness is not helpful in understanding Sub-argument 3. (Use of 'collapse' in 'a country collapses' seemingly sits well with this medical metaphor; in Section 5.2.3, the reader will see that this is not the case.)

In sum: it is hard to be completely sure of the logical structure of Sub-argument 3. Perhaps Hitchens' style is often allusive and thus can pose problems for argument identification generally. A more suspicious position might go something like this: Sub-argument 3 is a smokescreen and as such an obfuscatory rhetorical device (Bowell and Kemp 2010, p. 49). For many, the USled intervention of Iraq is difficult to support after the event since a key reason given for the intervention - that Iraq had in 2003 an active Weapons of Mass Destruction (WMD) programme turned out to be erroneous. Hitchens needs to deflect attention away from the issue of WMD. One way of doing this is by being allusive. This is why he uses an extended metaphor which is, in part, obscure ('a country... succumbs to trauma' [29]). Another way of avoiding reference to the non-existence of WMDs is by alluding to Saddam Hussein's genocidal past. Hitchens cannot, however, explicitly argue that the intervention was humanitarian in order to prevent (worsening) genocide; the intervention was not prosecuted for this reason since, unsurprisingly, there was no genocide in Iraq immediately before the 2003 intervention. ${ }^{14}$ This is why the references to Saddam's genocidal past in Sub-argument 3 are oblique. ${ }^{15}$ I should stress that this is a speculative interpretation.

\subsubsection{Supra-argument}

Hitchens says that former President Bush's speech was:

...wrongly believed to have focused on only two aspects of the [Iraq] problem, namely the refusal of Saddam's regime to come into compliance on the resolutions concerning weapons of mass destruction and the involvement of the Baathists with a whole nexus of nihilist and Islamist terror groups. [13]

Here, I think Hitchens is engaging in a rebuttal of the commonly held view that the only reasons for the 2003 Iraq intervention were that Saddam had a WMD programme and that he had links with 'Islamist terror groups'. But, Hitchens does not specify what the other aspects of the 'Iraq 
problem' were that Bush mentioned. Determination of the relevance of what Hitchens has written for the identification of (implicit) premises is frustrated. ${ }^{16}$ Moreover, Hitchens mentions that the US went into Iraq 'for the right reasons' [34]. Do these reasons include the ones in President Bush's speech which are not specified? It is difficult to know.

In [32], Hitchens says explicitly that 'the right thing' to do in relation to Burma, Darfur and Rwanda 'cannot be known in advance'. Is, then, Hitchens analogously implying that the 'right reasons' [34] for the US intervening in Iraq must include the post hoc ones of Sub-argument 2? It is difficult to tell and thus hard to know whether or not Sub-argument 2 is part of the Supra-argument. Again, comprehensive understanding of the text is impeded.

\subsubsection{Discussion}

I should emphasise that it is possible to isolate into arguments most of Hitchens' persuasion text. Sub-argument 1 is identifiable (although one could argue that there is a potential processing stutter created by inclusion of the book title ${ }^{17}$ ); all of Sub-argument 2 is identifiable. Whether or not Subargument 3 is deliberately obfuscatory, it is still in my opinion unhelpfully allusive in parts and as a result I am neither sure of my recovery of implicit premises nor my isolation of its conclusion (hence my use of question marks in the text annotation of Section 3.1.4).

As far as the Supra-argument goes, I am fairly confident of most of my reconstruction; this is because Hitchens has provided clear structural links between [34] and Sub-argument 1 and Subargument 3. (One could still argue that it would have been more helpful if these links had come much sooner in the text since the reader cannot fully appreciate the overall (Supra-) argument until almost the last sentence.) However, it is ambiguous whether or not i) Sub-argument 2 is part of the Supra-argument; ii) the implied other reasons for the intervention in Iraq (as laid out in President Bush's speech) [13] are also part of the Supra-argument. This is why I employ question marks in the text annotation of Section 3.1.5.

In sum: I cannot know whether or not Hitchens has a strategy of obfuscation in parts of his persuasion text. ${ }^{18}$ I can, however, make the reasonable claim that there are areas in his text's arguments which are not so straightforward to identify. In turn, this creates impediments for critical assessment of the logical soundness of Hitchens' argument. Despite these impediments, in Section 5, I show how the corpus-based strategy of Electronic Deconstruction can still potentially afford critical engagement with Hitchens' persuasion text. This is because its evaluative basis is the cohesive structure of a persuasion text which, as a set of surface features, is usually much easier to identify than all premises of an argument relevant to its conclusion, particularly where these are implicit premises or it is difficult to ascertain relevance.

In Section 2, I laid out the first part of Electronic Deconstruction - the identification of the cohesive structure of arguments in a persuasion text and how a corpus linguistic software tool can assist this. In Section 3, the second part of Electronic Deconstruction, I identified arguments in relation to their cohesive structure. Section 4, the third part of my outlining of Electronic Deconstruction, lays out the theory and method for deconstructing a persuasion text's cohesive structure. Since Electronic Deconstruction employs the concept of 'collocation', an important one in corpus linguistics, this is where I begin.

\section{Electronic deconstruction III: theory and method}

\subsection{Collocation and t-score}

Corpus linguistics is the investigation of corpora or large collections of electronic texts. There are a number of advantages to being able to investigate a very large corpus of a language. First, corpus 
linguists are able to discover things about language use which may otherwise remain invisible. Second, investigation of a corpus provides a quantitative, and thus robust, basis for confirming or falsifying intuitions about language use.

Exploration of large corpora by corpus linguists has revealed language use to be much more patterned than was previously thought. By patterned I mean that any word - whether lexical or grammatical - regularly co-occurs with other words. One type of language patterning which corpus analysis reveals to be especially common is collocation - a statistically significant local association between words. So, for example, a common collocate of 'intervention' is 'health'. The statistical measure, $t$-score, indicates the strength of attraction of words in collocations. A $t$-score of more than 2 is 'normally taken to be significant' (Hunston 2002, p. 72) but a $t$-score in double figures is very significant (Hunston 2001, p. 16). ${ }^{19}$

The Oxford English Corpus (OEC) is an example of a very large, predominantly web-based corpus. It currently consists of around two billion words of texts across a wide number of genres such as news, magazine articles and message board postings in UK, US, Australian and other national varieties of English. ${ }^{20}$ All OEC texts are from 2000 onwards; new material is continuously collected and added every few months. ${ }^{21}$ Given its range and balance of genres, as well as its size, and that it is used by Oxford University Press as the basis for its dictionary making, it is regarded as an authoritative basis for judgements about contemporary language use. In the OEC, 'health' collocates with 'intervention' 1395 times. The $t$-score for this collocation is 36.9 , which means this is a very statistically significant collocation. One may, of course, intuit that 'health' collocates with 'intervention' but, without the $t$-score information, we would not know so readily whether this collocation is fairly or very common.

The word being investigated for its collocational behaviour - in the above example, intervention' - is referred to as the node word. The number of words chosen either side of the node word to determine the scope of the investigation is known as the span. Five places to the left of a node word, and five places to the right of it, is the standard span for searching for collocation in corpus linguistics (Jones and Sinclair 1974). This standard span is referred to, in short, as an $n \pm 5$ span (where $n=$ node word). The $t$-score value above for collocation of 'health' and the node word 'intervention' is for an $n \pm 5$ span.

\subsection{Normal discussion of topics, large corpora and collocation patterns}

From the 1960s up until the very recent past, the largest electronic corpora have consisted of no more than millions of words (e.g. the 100-million-word British National Corpus completed in $1994^{22}$ ). With the advent of the world-wide-web, there is now a huge amount of electronic text which can be harvested for corpora creation; this is beginning to lead to web-based corpora consisting of billions of words, such as the OEC. The much greater size of web-based corpora, and their contemporary nature, means that not only can we know with greater certainty what normal collocation is in everyday language use, but also the following: what normal collocation is for the discussion of salient contemporary topics (e.g. the Iraq War).

The longer the search string in a corpus search, the more likely a topic can be designated. For example, instead of looking for collocates of 'intervention' - a very general notion - we could look for collocates of something much more specific, e.g. the topic 'intervention in Iraq'. For a corpus consisting of only millions of words, a collocate search of longer strings would not produce many if any results. However, with corpora consisting of billions of words, there are more likely to be collocate results for longer, and thus topic-designated, search strings. As a result, a web-based corpus, such as the OEC, can illuminate what the standard collocational terms are for discussion of a topic such as 'intervention in Iraq'. And, when I say what, I mean regardless of how these 
collocations are used in a speaker's or writer's evaluation. Let me explain why this is valuable for detecting instability in the cohesive structure of persuasion texts.

\subsection{Normal collocation for a topic, cohesion and electronic deconstruction}

\subsubsection{Absence from normal collocation}

It may turn out that there is an absence from normal collocation in use of a word in a persuasion text in relation to its topic (or sub-topic). This absence from normal collocation may just be a case of ellipsis with relevant contextual information supplied elsewhere in the text. Even if it not a case of ellipsis, the absence of normal collocation for the topic (or sub-topic) may not be deliberate. Alternatively, the author may have intentionally avoided normal collocation for a particular topic because otherwise its inclusion would undo the argumentative line they have constructed. ${ }^{23}$

\subsubsection{Exploring possible tensions in cohesive structure}

Electronic Deconstruction explores, via a very large corpus, potential tensions between normal collocation in discussion of the persuasion text's topic and the way in which discussion of the topic in an argument is collocated. If the analyst finds that there is an absence from normal collocation for the topic (or sub-topics), the next part of the procedure is the following: bestowing normal collocation on the text and examining whether or not this affects the consistency of its cohesive structure. A persuasion text's credibility is dependent, amongst other things, on its cohesion. If the cohesive structure is found to be unstable on bestowing normal collocation for that topic (or sub-topic), the credibility of the persuasion text diminishes.

Echoing what I wrote earlier, just because an analyst discovers that there is an absence from normal collocation, this does not mean that this is deliberate. That said, Electronic Deconstruction highlights that not employing normal collocation for discussion of a topic could be a hostage to fortune. If an author has not provided good reasons for avoiding how a topic (or sub-topic) is normally collocated, their persuasion text could be potentially vulnerable to electronic deconstructive analysis once normal collocation is bestowed.

Deconstruction with the most impact will be that which relates to the whole of the persuasion text or at least to significant portions of it. For this reason, the procedure seeks out possible deconstruction which affects the cohesive structure of any Sub-arguments or a Supra-argument in a persuasion text. An analyst may begin on the basis of an intuition that there exists an absence from normal collocation in the persuasion text, or on a more trial and error basis.

\subsubsection{Reducing subjectivity and electronic deconstruction}

If we do not know much about a persuasion text's topic (or sub-topic), we may not intuit absence from normal collocation and just assume the cohesive structure is stable. Electronic Deconstruction, as I will show, is a useful way of revealing instability in a persuasion text's cohesive structure for the unsuspecting. Even if absence from normal collocation can be intuited because the analyst has knowledge of the topic (or sub-topic), what is to prevent the charge that this is a reflex of the subjectivity of the analyst? The intuition of absence from normal collocation could, in theory, be batted back to the analyst by the author as 'well, just that's your opinion'. Since Electronic Deconstruction draws on corpus linguistic method and statistical metrics, subjectivity is significantly reduced in judgements of absent meaning and, in turn, in evaluations of instability in cohesive structure.

Drawing on the two-billion word OEC, Section 5 demonstrates Electronic Deconstruction by performing the following: evaluative analysis of the stability of the cohesive structure of 
Hitchens' persuasion text which WMatrix helped to illuminate (see Section 2.2). The OEC is made available through Sketchengine (http://www.sketchengine.co.uk/), the software I use to search through this corpus. Since the OEC consists of website material from 2000 onwards, this makes it very useful for investigating collocational norms for discussion of the US-led coalition intervention of Iraq in 2003. Through comparison with these norms, I will show that the cohesive structure of arguments in Hitchens' text deconstructs. For all OEC investigations, I use the same word span $n \pm 5$.

\section{Electronic deconstruction IV: deconstructive analysis of a persuasion text}

\subsection{Deconstruction in Sub-argument 1 and the supra-argument}

\subsubsection{Normal collocation for 'intervention in Iraq'}

In Sub-argument 1, Hitchens uses the expression 'Anglo-American intervention in Iraq' [1]. This cohesively links with 'intervene' [34] in the Supra-argument. In the OEC, 'Anglo-American' occurs only once as a collocate of 'intervention in Iraq' and unsurprisingly with no statistical significance. In contrast, 'military' collocates with 'intervention in Iraq' 126 times ( $t$-score 11.2). In fact, 'military' is the highest lexical collocate of 'intervention in Iraq'. These collocation results tell us that the intervention in Iraq has been discussed much more in 'military' than in 'AngloAmerican' terms. (Moreover, it is worth flagging that Hitchens refers to 'intervention' in [16] and 'intervene' in [34] without modification from 'militar(il)y' either.)

I should stress that finding out what normal collocation is for 'intervention in Iraq' is not the same as finding out an opinion, i.e. how that normal collocation is used in an evaluation. To do that, we would need to go beyond collocation and explore the clauses and sentences in which 'military' collocates with 'intervention in Iraq'. Studying the wider context of instances of this collocation in the OEC reveals that sometimes 'military intervention in Iraq' is assented to, sometimes it is disagreed with or sometimes it is described neutrally, e.g. 'the military intervention in Iraq was justified/a disaster/took place in 2003'. Corpus evidence below for other normal collocation, likewise, does not tell us about the evaluative nature of opinions expressed.

It is interesting to see what happens in Sub-argument 1 if we replace the relatively rare collocate of 'intervention in Iraq', 'Anglo-American', with the most common lexical collocate, 'military':

[1] An 'anniversary' of a 'war' is in many ways the least useful occasion on which to take stock of

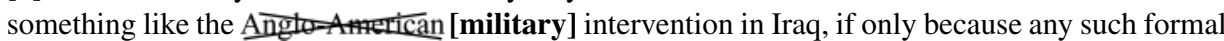
observance involves the assumption that a) this is, in fact, a war and b) it is by that definition an exception from the rest of our engagement with that country and that region.

Replacing 'Anglo-American' [1] with 'military' creates tensions for an argument whose cohesion depends to a large degree on negating the idea that the 'Anglo-American intervention in Iraq' was a discrete war and thus an exception from US involvement in Iraq since 1968. Since 'military' has such strong associations of 'war', it would not help Hitchens to collocate 'military' with 'intervention in Iraq'. Indeed, out of the 391, 873 instances of 'military' in OEC, 'war' collocates 3913 times ( $t$-score 62.5) and 'War' collocates 2345 times ( $t$-score 48.4). Combined, at 7052 instances, this makes 'W/war' the 10th most common collocate of 'military'.

The collocation absence of 'military' may not, of course, be deliberate. However, if it were a deliberate omission and, if Hitchens had responded to this electronic deconstruction, he might have argued that the reason he did not modify 'intervention in Iraq' with 'military' is he did not want to create the false impression that the intervention was a war. However, the corpus evidence for 'intervention in Iraq' creates difficulty for this kind of retort because Hitchens would also have 
to demonstrate that common discussion of the intervention in Iraq in military terms is misguided whether people agree or not with the intervention. I shall show later that the fact 'military' is the most common collocate of 'intervention in Iraq' creates further difficulties for cohesion in Hitchens' persuasion text.

\subsubsection{Normal collocation for 'hostilities'}

Hitchens uses 'hostilities' [4] in:

[4] But when I wrote the essays that go to make up A Long Short War: The Postponed Liberation of Iraq, I was expressing an impatience with those who thought that hostilities had not really 'begun' until George W. Bush gave a certain order in the spring of 2003. [my bold]

Sentence [4] forms part of Sub-argument 1. Below, I show how Hitchens' use of 'hostilities' [4] inadvertently leads to tensions in both Sub-argument 1 and the Supra-argument. I achieve this by contrasting his use of 'hostilities' with normal collocation for this term. (When two figures appear in brackets below, the first figure is the frequency of a collocate and the second figure is its $t$-score.)

There are 5914 instances of 'hostilities' in the OEC. The first, second and third most common lexical collocates are 'end' (615; $t$-score 24.7), 'cessation' (392; $t$-score 19.8) and 'outbreak' (230; $t$-score 15.2). 'Began' (126; $t$-score 11.1) is the sixth most common lexical collocate and 'ended' $(123 ;$-score 11.1$)$ the seventh. 'War' (134; $t$-score 11.4$)$ is the fifth most common lexical collocate of 'hostilities'. Conventionally when 'hostilities' is used, the beginning or end of a particular war is communicated, such as in:

A caravan of Japanese well-wishers and Project A50 boosters will fly to 32 U.S. cities following the official ceremonies, spreading the word that Japan has not forgotten American largesse in the half a century following the cessation of World War II hostilities... [my bold]

The third most common grammatical collocate of 'hostilities' is 'in' (1638; $t$-score 38.1$)$; this reflects the fact that 'hostilities' are not just commonly discussed in relation to a particular war and its outbreak or cessation, but in relation to a particular place, such as in:

He said a lot of trade opportunities would be achieved by Zambia, especially in the cement industry following the end of hostilities in Burundi. [my bold]

Indeed, while 'Iraq' is the fourth most common lexical collocate of 'hostilities' (212; $t$-score 14.5), 'in Iraq' is also a significant collocate ( 37 ; $t$-score 6.0). Furthermore, it is common for 'hostilities' and 'in' to collocate with a particular time; commonly a year collocates with 'hostilities', such as in:

Following the cessation of 'hostilities' in 1763, Washington began to argue for the land grants promised to the veterans in exchange for military service. [my bold]

In sum, by exploring collocation of 'hostilities', I am able to create a picture of how one aspect of the topic of 'war' is normally discussed: when the word 'hostilities' is used, it is normal for places and/or points of time and/or the particular war to be indicated.

Let me now bestow normal collocation for 'hostilities' where the term is used in Sub-argument 1 and explore possible deconstruction in cohesive structure. To assist exploration, I reproduce Sub-argument 1 and annotate common collocation around 'hostilities' together with making other relevant annotations; I also reproduce [34], a key sentence for the structure of the Supra-argument:

Premise: A war between two countries is by definition an exception in how those two countries engage with one another. [1]

Premise: Hostilities did not begin in 2003 (though it is unclear in Hitchens' text when they did begin). [4] ['Hostilities' commonly collocates with 'war' and thus ACTION as well as dates which indicate beginnings/ends of wars] 
Premise: Heavy US involvement in the affairs of Iraq began no later than 1968. [5]

Premise: [There was] a decision [MENTAL EVENT] by the US to acquiesce in the Iraqi invasion of Iran. [6]

Premise: Kissinger [gives] faux support for Kurdish revolutionaries. [7]

Premise: Saddam Hussein courts Washington. [8]

Premise: Saddam Hussein decides [MENTAL EVENT] to 'engulf' Kuwait. [8]

Premise: There was a really quite high level of public participation in US foreign policy in decisions [MENTAL EVENT] taken to recover Kuwait, the decision [MENTAL EVENT] to leave Saddam in power; the decision [MENTAL EVENT] to impose international sanctions on Iraq; the decision [MENTAL EVENT] to pass the 1998 Iraq Liberation Act. [9]

Premise: Baghdad outrageous[1y] flouted the resolutions on WMD compliance. [13-14]

Premise: 'We became steadily more aware that the option was continued collusion with Saddam or a decision [MENTAL EVENT] to have done with him'. [11]

Conclusion: We were never... 'lied into war' [10], i.e., the 'Anglo-American intervention in Iraq' [1] was not a discrete war but a continuation of US involvement in Iraq since (no later than) 1968.

[34] We were already deeply involved [cohesive link to Sub-argument 1] in the life-anddeath struggle of that country, and March 2003 happens to mark the only time that we ever decided [MENTAL EVENT] [cohesive link to Sub-argument 1] to intervene [cohesive link to Sub-argument 1], [...]

From qualitative exploration of the persuasion text, assisted by the WMatrix analysis of semantic domains in Section 2, we know that:

(1) Sub-argument 1 constructs US involvement in the 'affairs' of Iraq [5] from 1968 until before the 2003 intervention as a continuity of decisions;

(2) in the Supra-argument, the 2003 US 'decision to intervene' [34] is constructed as another decision in this continuity of decisions.

However, the corpus evidence tells us that 'hostilities' [4] in Sub-argument 1 must be in tension with this cohesive pattern of a continuity of mental events in Sub-argument 1 and the Supra-argument. This is, first, because normal collocation for 'hostilities' overwhelmingly involves action - the action of war. Second, that normal collocation for 'hostilities' involves indicating the beginnings and ends of wars is in tension with Hitchens not explicitly indicating, via dates, the end of any 'hostilities' referred to in Sub-argument 1. For example, he flags (i) that Saddam Hussein was 'in favor' in Washington [8]; (ii) US acquiescence in the Iraqi invasion of Iran [6]; more broadly, Hitchens writes that the US was involved in the 'life-struggle' of Iraq [34]. In other words, there were periods where hostilities had ended/not begun again between US and Iraq.

In sum, while Hitchens constructs US involvement in Iraq from 1968 to 2003 as a continuity of decisions, normal collocation for 'hostilities' conflicts with this construction. Unwittingly, for Hitchens, 'hostilities' is a 'stray signifier' which leads to further instability in the cohesion of Sub-argument 1.

\subsection{Deconstruction in Sub-argument 3 and the supra-argument}

\subsubsection{Normal collocation for 'intervention in Iraq'}

In Section 3.2.1, I highlighted how Hitchens uses, as part of Sub-argument 3, an extended medical metaphor such that the US is a quasi-doctor who 'intervenes' [34] in a 'traumatised' [29] Iraq, the US having had 'responsibility' [29] and 'involvement' [29, 34] for this quasi-patient's 'life and death struggle' [34] for many years. 
Corpus evidence supports an interpretation that an audience could well infer this medical allusion: the most common lexical collocate of 'intervention' is 'health' (1395; $t$-score 36.9); other collocates of 'intervention' that can be regarded as falling under a 'health' semantic field, and carrying statistical significance, are 'medical' $(837 ; t$-score 28.7$)$, 'care' (748; $t$-score 26.8), 'treatment' $(607 ; t$-score 24.3), 'surgical' (566; $t$-score 23.8), 'patients' $(519 ; t$-score 22.4) and 'trauma' ( $25 ; t$-score 5$)$ itself. I have flagged cohesion for this extended medical metaphor below in bold:

[28] There is, however, one position that nobody can honestly hold but that many people try their best to hold.

[29] And that is what I call the Bishop Berkeley theory of Iraq, whereby if a country collapses and succumbs to trauma [MEDICAL], and it's not our immediate fault or direct responsibility, then it doesn't count, and we are not involved.

[30] Nonetheless, the very thing that most repels people when they contemplate Iraq, which is the chaos and misery and fragmentation (and the deliberate intensification and augmentation of all this by the jihadists), invites the inescapable question: What would post-Saddam Iraq have looked like without a coalition presence?

\section{Paragraph $G$}

[31] The past years have seen us both shamed and threatened by the implications of the Berkeleyan attitude, from Burma to Rwanda to Darfur.

[32] Had we decided to attempt the right thing in those cases (you will notice that I say 'attempt' rather than 'do', which cannot be known in advance), we could as glibly have been accused of embarking on a 'war of choice'.

[33] But the thing to remember about Iraq is that all or most choice had already been forfeited.

[34] We were already deeply involved in the life-and-death struggle [MEDICAL] of that country, and March 2003 happens to mark the only time that we ever decided to intervene [militarily], after a protracted and open public debate, on the right side and for the right reasons. [my bold]

In [34], Hitchens uses the expression 'we decided to intervene' where 'we' links back to 'Anglo-American' [1]. But, we know from Section 5.1.1 that 'military' is the highest lexical collocate of 'intervention in Iraq', that is, this is normal collocation. Modifying 'intervene' [34] with 'militarily', as I have done above, conflicts with the medical-related cohesive chain. Cohesion in Sub-argument 3 is destabilised with knock-on effect on its credibility.

\subsubsection{Normal collocation for hypothetical and actual humanitarian interventions}

In Section 3.2.1, I argued that Sub-argument 3 can be seen as implying that the Iraq intervention was humanitarian and thus morally superior to the lack of interventions in Burma, Darfur and Rwanda. Using Sketchengine software, I investigate the extent to which 'military intervention in' and 'humanitarian intervention in' collocate with any of these places in the OEC. I use these multi-word units for the sake of consistency with Section 5.1.1. There were no results for Burma or Rwanda but there were for Darfur/Sudan: 'humanitarian intervention in' + 'Darfur' (4; $t$-score 4); 'military intervention in' + 'Sudan' (14; $t$-score 3.7). Moreover, the OEC provides evidence of collocation with actual humanitarian interventions in the Balkans and Somalia. For 'humanitarian intervention in', we have: Bosnia ( $7 ; t$-score 2.6) and Somalia $(7 ; t$-score 2.6$)$; and for 'military intervention in' we have: Balkans (15; $t$-score 3.9), Kosovo (21; $t$-score 4.6) and Somalia (17; $t$-score 4.1).

The corpus analysis suggests that actual humanitarian interventions, and hypothetical (at the time of writing) humanitarian interventions for Burma, Darfur and Rwanda, are also discussed in military terms. This makes perfect sense since humanitarian interventions, particularly where genocide is involved, will usually require military intervention. (This is supported by the information in the UN weblink in footnote 12.) What this means is that for Hitchens to create credibly, 
Table 2. The 10 highest lexical collocates for the broadly conceived lemma, COLLAPSE, filtered for COUNTRY.

\begin{tabular}{lcc}
\hline Lexical collocate & Frequency & $T$-Score \\
\hline economic & 63 & 7.9 \\
economy & 28 & 5.3 \\
Soviet & 22 & 4.7 \\
system & 19 & 4.3 \\
Union & 18 & 4.2 \\
system & 39 & 6.2 \\
following & 16 & 3.9 \\
banking & 12 & 3.5 \\
banks & 12 & 3.5 \\
regime & 30 & 3.4 \\
developing & 30 & 3.4 \\
financial & 30 & 5.4 \\
\hline
\end{tabular}

in Sub-argument 3, the seeming implication that the Iraq invasion was some kind of humanitarian intervention, it would be unusual if it were not also associated with a military intervention. However, as already mentioned, collocating 'intervene' [34] with 'militarily' would conflict with the medical-related cohesive chain. If it really is the case that Hitchens deliberately avoids modification of 'intervene' [34] in order to help to create a smokescreen via implication that the US-led coalition invasion of Iraq was a humanitarian intervention, then a deliberate omission would be hoist by its own petard.

\subsubsection{Normal collocation for 'a country collapses'}

In this section, I highlight how normal collocation for 'a country collapses' also creates tensions in the cohesion of the extended medical metaphor. At first sight, it might appear that 'a country collapses' sits well with the extended metaphor of Iraq as patient and US as doctor. Exploring normal collocation in relation to 'a country collapses', I show that this is not the case.

There are 87,462 instances of the broadly conceived lemma, COLLAPSE. ${ }^{24}$ Using Sketchengine software, I filtered all these instances on the lemma COUNTRY (for an $n \pm 5$ span) given that Hitchens uses the expression 'a country collapses' [29]. This left me with 676 instances of COLLAPSE collocating with COUNTRY in texts in OEC. I then calculated collocation for $n \pm 5$ span. The most common lexical collocates are 'economic' ( $63 ; t$-score 7.9$)$ and 'economy' (28; $t$-score 5.3); other related collocates are 'banking', 'banks' and 'financial' (see Table 2).

Here is an example from OEC:

...hundreds of thousands of Argentines clamour to escape their country's slide towards economic collapse. [my bold]

Even for other common collocates, such as 'Soviet Union', it is common for there to be economic/financial contexts such as in:

Russia and other East European countries, whose economies collapsed along with the Soviet Union, now emit far less carbon dioxide than in the 1990 baseline year... [my bold].

This is not surprising since economic factors played a highly significant role in the collapse of the Soviet Union. ${ }^{25}$

Prototypically, if a country is said to collapse, the OEC informs us that this is related to economic reasons. Put another way, the OEC tells us that default understanding of 'a country collapses' is likely to treat 'collapse' as a dead metaphor, a convenient shorthand description for deterioration 
in a country's economy. However, this conventional understanding of 'a country collapses' is in tension with Hitchens' use of the expression in constructing US involvement in Iraq as a live medical metaphor. ${ }^{26}$ That conventional usage of 'a country collapses' does not, in fact, sit well with an extended medical metaphor inadvertently leads to further deconstruction of cohesion in Subargument 3, and the conclusion of the Supra-argument. For Hitchens to prevent this deconstruction, he could just be clearer about what he means by 'a country collapses and succumbs to trauma' [29]. If the vagueness of this larger expression is, indeed, a deliberate obfuscatory strategy then, on an electronic deconstructive reading, it would be hoist by its own petard.

\section{Endpoints}

This article has highlighted an approach to the critical analysis of persuasion texts: Electronic Deconstruction recognises the opportunities for critical analysis that derive from the existence of very large corpora - opportunities for making visible possible invisible tensions in cohesive structure. Drawing on corpus linguistic method, the strategy of Electronic Deconstruction reveals tensions between normal collocation for discussion of a topic (or sub-topic) and the way in which that topic (or sub-topic) is collocated in an argument - whether an author's avoidance of normal collocation for a particular topic of a persuasion text is deliberate or not. Bestowing normal collocation for that topic on the argument may undo the cohesive structure of the persuasion text and thus reduce its credibility. I have demonstrated this critical argument analysis strategy on one persuasion text. Clearly, more work using the approach of Electronic Deconstruction on a variety of arguments with different topics is required. I should say, also, that I have not, necessarily, exhausted all the cohesive instability of Hitchens' text relative to normal collocation.

The strategy of Electronic Deconstruction highlights the hostage to fortune of not discussing a topic (or sub-topic) using its normal collocation. In saying this, I am not suggesting that arguers are obliged to use normal collocation for a topic at all times. Such a position would not be appropriate since absence from normal collocation for a topic may, in fact, have no negative effect on the cohesive structure of an argument - it all depends on the nature of the argument and its cohesion. What I would contend is that where a persuasion text can be shown to electronically deconstruct, it would have been in the author's interests to provide good and convincing reasons for why they have not employed normal collocation for their persuasion text's topic.

I have indicated above a number of advantages of Electronic Deconstruction. I do not wish, however, to present it as free of limitations. If an arguer has used normal collocation for discussion of a particular topic, then Electronic Deconstruction cannot operate. Second, as I have just indicated, even if there is an absence from normal collocation, this may not necessarily lead to deconstruction. For example, corpus-based explorations of Sub-argument 2 had little effect on its cohesion, which is why there is no report of its electronic deconstructive analysis in Section 5. As another example, Hitchens may have used the expression 'Anglo-American intervention in Iraq' in a completely different argument where he does not negate that the Iraq intervention was a war. Because of this, bestowal of the normal collocate 'military' could have no effect at all on the cohesive structure of this hypothetical argument. In sum: not all arguments can necessarily be electronically deconstructed.

In order to assess the logical soundness of arguments, comprehensive reconstruction of premises and conclusions is necessary. However, there may be parts of an argument where reconstruction is frustrated. This may be, for instance, because the author has been stylistically clumsy, or perhaps the author deliberately obfuscates their arguments because they know they are weak. Whatever the reason for frustrations in reconstruction, incompleteness in identification of logical structure can make critical assessment of the logical soundness of an argument difficult. An 
advantage of Electronic Deconstruction, as I tried to show, is that it can still potentially facilitate a critical engagement with a persuasion text. This is because its evaluative focus is the argument's cohesive structure, something which is usually easier to identify - as a set of surface textual features - than an argument's logical structure, particularly where the latter includes implicit premises and it is difficult to ascertain relevance. ${ }^{27}$

\section{Acknowledgements}

Many thanks to Guy Cook, Ann Hewings, Catherine Williams and the anonymous reviewers for helping to improve previous drafts.

\section{Notes}

1. Corpora have been used for a variety of purposes but their use for examining argumentation has only been recent (e.g. Reed 2006; Degano 2007).

2. It is also referred to as 'standardisation' (e.g. Govier 2009).

3. The term 'deconstruction' also characterises the approach to reading of the philosopher, Derrida (1981), where a text is shown to consist of undecideable meanings. Electronic Deconstruction, with its focus on the instability of cohesion in a persuasion text, is very different to Derrida's focus.

4. Natural language arguments frequently are elliptical, since they usually leave out premises that according to formal logic are necessary for valid conclusions (Govier 1987; Anderson, Chinn, Chang, Waggoner, and Yi 1997). Reconstructing implicit premises is not always a straightforward task. This is especially so if it is difficult to reconstruct an argument's structure.

5. See http://www.slate.com/id/2186740/. [Accessed August 2012].

6. Lexical words carry the main information content of a text and belong to four grammatical classes: nouns ('Peter', 'Moscow', 'dictionary'); lexical verbs ('walk', 'think', 'pray'); adjectives ('hot', 'thirsty', 'angry'); adverbs ('slowly', 'recently', 'often'). Grammatical words are words that express grammatical relationships and classifications, such as determiners ('the'), conjunctions ('if') prepositions '(in'), pronouns ('he') and auxiliary verbs ('is' in 'he is wanted for murder').

7. The semantic tagger is known as USAS (UCREL Semantic Analysis System). For more information, see: http://ucrel.lancs.ac.uk/usas/. [Accessed August 2012].

8. WMatrix has online access to one reference corpus - the British National Corpus (BNC) Sampler. This consists of around one million words each of the BNC Sampler spoken corpus and the BNC Sampler written corpus (the whole of the BNC consists of 10 million words of spoken and 90 million words of written English).

9. On the rule of thumb that 'we should at least try to obtain reference corpora which reflect some aspect of the smaller corpus or text sample we are studying' (Baker 2006, p. 43), I chose to compare the argument with the BNC Sampler written corpus. This contains material from books, periodicals and other sources covering a range of domains including fiction, science, social science, world affairs, commerce, arts, religion and leisure. This corpus is based on the original design of the BNC and is thus a 'balanced' corpus, representing a wide cross-section of written British English. The variety and balance of the corpus make it useful for my purposes since, in being fairly representative of written discourse, it will likely reveal statistically unusual features of Hitchens' text. More information can be obtained on the composition of the BNC Sampler written corpus at http://ucrel.lancs.ac.uk/bnc2sampler/sampler.htm. [Accessed August 2012].

10. Since a log likelihood of 6.63 is the cut-off for 99 per cent confidence of significance, WMatrix recommends looking at log likelihood values over 7 .

11. I do not discuss [35] since it just serves to reinforce the message of [34].

12. On the language of 'humanitarian intervention' and genocide from a United Nations perspective, both generally and specifically in relation to Rwanda, see: http://www.un.org/preventgenocide/ rwanda/responsibility.shtml [Accessed August 2012]. 
13. Other than with 'Anglo-American' and 'US'/'our', Hitchens does not modify the words he uses to refer to the Iraq invasion: 'intervention/intervene' [1, 13, 25] 'involvement'/'involve' [4, 21, 25], 'engagement' [1], 'enterprise' [14].

14. Hitchens' reference in [19] to 'the ever-present threat of a renewed genocide' is, in fact, a red-herring.

15. Infamous genocides conducted by Saddam Hussein include the An Afal genocide (1986-1989) (http://en.wikipedia.org/wiki/Al-Anfal_Campaign). [Accessed August 2012].

16. Sending the reader to the speech via the hyperlink [12] to work out the other reasons on their own is unfortunately not helpful. Former President George Bush Jr's speech is no longer available.

17. I would argue that there are at least two possible understandings of the text once the reader has read up to and including [5]. Both potentially come with problems for the reader's processing of Sub-argument 1. (a) Understanding I: the 2003 Iraq intervention was not an exception from US involvement in Iraq since 1968 and thus not a war.

In Sub-argument 1, Hitchens i) holds that a war between two countries is by definition an exception in how these countries engage with each other and ii) distances himself from the view that the 2003 intervention in Iraq is a war [1]. Reading up to and including [5], the reader could come to the view that Hitchens' argument is as follows: since the US has been continuously 'involved' in Iraq since 1968, the 2003 intervention was not an exception from this involvement and thus not a war. However, if this is the understanding that Hitchens intends the reader should generate, why, then, does he include a book title which seems to refer explicitly to the 2003 Iraq intervention as a war [4] - "A Long Short War: The Postponed Liberation of Iraq'? (my emphasis). One possible reading of [4] is that it creates a tension in Sub-argument 1; as a result, the reader may be confused by Hitchens' text only five sentences in which, in turn, could be a problem for comprehensive identification of the argument.

(b)Understanding II: the US has been at 'war' with Iraq since 1968

Another possible understanding of the text up to and including [5] is that the reader sees the book title 'A Long, Short War' as relating to the period 1968-2008. By this I mean the reader may understand Hitchens as arguing that the 2003 intervention in Iraq and onwards is not a discrete war because the US had been continuously at 'war' with Iraq since (no later than) 1968 up until 2008, either in the direct sense of war such as in Gulf War I (1990-1991) or in the indirect sense of the CIA allegedly abetting the 1968 coup [5]. This understanding would be wrong because [6], [8] and [34] indicate that the US was not continuously at war with Iraq over this period. This misunderstanding - hardly the fault of the reader since Hitchens does not indicate when the book was published (in fact, in 2003) - is compounded by Hitchens i) negating that 'hostilities began' in 2003 but ii) not being explicit when hostilities started. Hitchens' mention of the book title may just be an innocent inclusion because his motivation is, in part, to promote his book. A more suspicious perspective - albeit a speculative one - is that he includes the book title as a rhetorical ploy of obfuscation in order to slow down a reader's engagement with the argument. The reader's processing of the argument may be retarded by thinking there is an inconsistency in the argument (along the lines of a)) or by making a false assumption (along the lines of b)) which may or may not be annulled in processing the remainder of the argument. Retarding a reader's engagement with his persuasion text would be in Hitchens' interests if he regards his arguments as weak.

18. See Paglieri (2009) on obfuscation and the difficulties this entails for reconstruction of arguments.

19. For more information on $t$-score, see Barnbrook (1996).

20. See: http://www.oxforddictionaries.com/page/552 for more information on the OEC. [Accessed August 2012].

21. All frequencies and $t$-scores in the Section 5 analyses were checked August 2012.

22. http://www.natcorp.ox.ac.uk/corpus/index.xml [accessed August 2012]

23. By lack of normal collocation, I am not referring to playful, creative collocation, such as highlighted in Partington's (1998) corpus-based study. Playful, creative collocation is often if not usually inappropriate in the serious genre of argument.

24. The lemma of a word consists of all its grammatical instances. Lemmas are indicated conventionally by capitals. The noun lemma COLLAPSE includes the noun singular form 'collapse' and the noun plural form 'collapses'. The verb lemma COLLAPSE includes the verb forms 'collapse', 'collapses', 'collapsed', 'collapsing'. A broad conception of the lemma COLLAPSE would include its noun and verb forms. 
25. http://en.wikipedia.org/wiki/Dissolution_of_the_Soviet_Union [Accessed August 2012].

26. See O'Halloran (2007) on the value of using corpus linguistic method for helping differentiate between 'dead' and 'live' metaphor.

27. See also O'Halloran $(2010,2011,2012)$ for related work with different methodological emphases.

\section{References}

Anderson, R.C., Chinn, C., Chang, J., Waggoner, M., and Yi, H. (1997), 'On the Logical Integrity of Children's Arguments', Cognition and Instruction, 15, 135-167.

Baker, P. (2006), Using Corpora in Discourse Analysis, London: Continuum.

Barnbrook, G. (1996), Language and Computers: A Practical Introduction to the Computer Analysis of Language, Edinburgh: Edinburgh University Press.

Bowell, T., and Kemp, G. (2010), Critical Thinking (3rd ed.), Abingdon, UK: Routledge.

Degano, C. (2007), 'Presupposition and Dissociation in Discourse: A Corpus Study', Argumentation, 21, 361-378.

Derrida, J. (1981) [1972], 'Plato's Pharmacy', in Dissemination, trans. B. Johnson, Chicago: University of Chicago Press, pp. 63-171.

Dunning, T. (1993), 'Accurate Methods for the Statistics of Surprise and Coincidence', Computational Linguistics, 19(1), 61-74.

Govier, T. (1987), Problems in Argument Analysis and Evaluation, Providence, RI: Foris.

Govier, T. (2009), A Practical Study of Argument (7th ed.), Florence, KY: Wadsworth.

Halliday, M., and Hasan, R. (1976), Cohesion in English, Harlow, UK: Longman.

Hunston, S. (2001), 'Colligation, Lexis, Pattern, and Text', in Patterns of Text: In Honour of Michael Hoey, eds. M. Scott and G. Thompson, Amsterdam, The Netherlands: John Benjamins, pp. 13-33.

Hunston, S. (2002), Corpora in Applied Linguistics, Cambridge: Cambridge University Press.

Jacobs, S. (2000), 'Rhetoric and Dialectic from the Standpoint of Normative Pragmatics', Argumentation, 14(3), 261-286.

Jacobs, S. (2009), 'Nonfallacious Rhetorical Design in Argumentation' in Pondering on Problems of Argumentation: Twenty Essays on Theoretical Issues, eds. F. Eemeren and B. Garssen, Berlin, Germany: Springer, pp. 55-78.

Jones, S., and Sinclair, J. (1974), 'English Lexical Collocations', Cahiers de Lexicologie, 24, 15-61.

O'Halloran, K.A. (2007), 'Critical Discourse Analysis and the Corpus-Informed Interpretation of Metaphor at the Register Level', Applied Linguistics, 28(1), 1-24.

O’Halloran, K.A. (2010), 'Critical Reading of a Text Through Its Electronic Supplement', Digital Culture and Education, 2(2), 210-229.

O’Halloran, K.A. (2011), 'Limitations of the Logico-Rhetorical Module: Inconsistency in Argument, Online Discussion Forums and Electronic Deconstruction', Discourse Studies, 13(6), 797-806.

O'Halloran, K.A. (2012), 'Electronic Deconstruction: Revealing Tensions in the Cohesive Structure of Persuasion Texts', International Journal of Corpus Linguistics, 17(1), 91-124.

Paglieri, F. (2009), 'Commentary on Frank Zenker's "Reconstructive Charity, Soundness and the RSACriteria of Good Argumentation"”, in Argument Cultures: Proceedings of OSSA 09, CD-ROM, ed. J. Ritola, Windsor, Canada: OSSA, pp. 1-8.

Partington, A. (1998), Patterns and Meanings, Amsterdam, The Netherlands: John Benjamins.

Rayson, P. (2009), Wmatrix: A Web-Based Corpus Processing Environment, Computing Department, Lancaster University. http://ucrel.lancs.ac.uk/wmatrix.

Reed, C. (2006), 'Preliminary Results from an Argument Corpus', in Linguistics in the Twenty-First Century, eds. Eloína Miyares Bermúdez and Leonel Ruiz Miyares, Newcastle upon Tyne, UK: Cambridge Scholars, pp. 185-196.

Walton, D. (2006), Fundamentals of Critical Argumentation, Cambridge: Cambridge University Press. 